Volume 4 • Nomor 2 • Februari 2021

Pege (Hal.) : $254-268$

(C) Universitas Pamulang

JL.Surya Kencana No.1 Pamulang, Tangerang Selatan - Banten

Telp. (021) 7412566, Fax (021) 7412491

website. :

urnalmarketing.unpam@gmail.com

\title{
Pengaruh Kualitas Pelayanan dan Promosi Terhadap Loyalitas dengan Kepuasan Sebagai Variabel Intervening (Studi Home Industri Produk Pakaian Sablon \& Bordir)
}

\author{
Nurmin Arianto ${ }^{1}$; Fiki Kurniawan ${ }^{2}$ \\ ${ }^{1}$ Dosen dan ${ }^{2}$ Alumni Mahasiswa Fakultas Ekonomi- Manajemen, Universitas Pamulang \\ Jl.Surya Kencana No.1, Tangerang Selatan ; email : nurmin1989@gmail.com
}

\begin{abstract}
Abstrak. Tujuan dari studi ini adalah untuk mencari tahu bagaimana pengaruh kualitas pelayanan, promosi terhadap kepuasan konsumen dan pengaruh kulitaspelayanan, promosi dan kepuasan terhadap loyalitas konsumen. Sifat dari studi ini adalah asosiatif dengan jumlah populasi yang digunakan dalam penelitian ini adalah konsumen sebanyak 1.078 dan teknik sample yang digunakan adalah sampel accidental sampling sedangkan teknik analisis data dalam penelitian ini dengan menggunakan menggunkan analisis jalur. Dari hasil penelitian yang dilakukan sebagain besar respoden dalampenelitian ini adalah Perempuan dengan usi 21-26th dengan sumber pendapatan lainya. Dari tanggapan responden bahwa Kualitas Pelayanan, Promosi dan kepuasan serta Loyalitas yang ada di perusahaan sudah baikn walaupun masih tersapat keluhan konsumen tentang produk ini dan dari hasil analisis bahwa Kualitas Pelayanan, Promosi dan kepuasan memiliki pengaruh terhadap Loyalitas serta Kualitas Pelayanan dan Promosi memiliki pengaruh terhadap kepuaan, sehingga kepuasan dapat menjadi mediator dalam mempengaruhi Kualitas Pelayanan an terhadap Loyalitas dan kepuasan dapat menjadi mediator dalam mempengaruhi Promosi terhadap Loyalitas.
\end{abstract}

Kata kunci: Kualitas pelayanan; Promosi; Loyalitas; Kepuasan.

Abstract. The aim of this research is to find out how the influence of service quality, promotion of consumer satisfaction and the influence of quality of service, promotion and satisfaction with consumer loyalty. This research is associative in nature with the population used in this study is 1,078 consumers and the sample technique used is accidental sampling while the data analysis technique in this study uses path analysis. From the results of research conducted by most respondents in this study are women with age 21-26th with other sources of income. From the respondent's ladder that Service Quality, Promotion and satisfaction as well as Loyalty in the company is already good even though there are still complaints from consumers about this product and from the results of the analysis that Service Quality, Promotion and satisfaction has an influence on Loyalty and Quality of Service and Promotion has an influence of aging, so satisfaction can be a mediator in influencing the Quality of Services to Loyalty and satisfaction can be a mediator in influencing Promotion of Loyalty.

Keyword: Service Quality; Promotion; Loyality; Satisfcation. 


\section{A. PENDAHULUAN}

Ketatnya persaingan antar perusahaan saat ini, sehingga perusahaan wajib untuk terus meningkatkan pelayanannya mengikuti kebutuhan dan harapan konsumen melalui pelayanan yang memuaskan, perusahaan yang akan memenangkan persaingan dan menguasai pasar adalah perysahaan yang memiliki kualitas, jika konsumen telah mendapatkan kepuasan dalam berbelanja pada Home Industri produk pakaian sablon \& bordir maka dapat dikatakan loyal terhadap produk tersebut, namun kenyataanya masih terdapat keluhan konsumen tentang keterlambantan pengiriman barang, hal ini juga bisa dilihat berdasarkan data yang diperoleh dari Home Industri Pakaian Sablon \& Bordir, sehingga Kualitas pelayanan dan Promosi yang diberikan masih kurang krena media promosi yang di gunakan hanya menggunakan social media, kartu nama, Stiker dan Buku Katalog dan hal tersebut menyebabkan konsumen kurang puas dan tidak loyal terhadap Home Industri hal ini juga dibuktikan dengan menurunya jumlah penjualan setiap tahunnya dimana penurunan drastis pada tahun 2018 yang disebabkan karena promosi yang dijalankan masih kurang. Berikut ini adalah rumusan masalah dan tujuan dalam penelitian ini:

1. Untuk mengetahui bagaimana pengaruh kualitas pelayanan terhadap kepuasan pelanggan pada Home Industri Produk Pakaian Sablon \& Bordir

2. Untuk mengetahui bagaimana pengaruh promosi terhadap kepuasan pelanggan pada Home Industri Produk Pakaian Sablon \& Bordir

3. Untuk mengetahui bagaimana pengaruh kualitas pelayanan terhadap loyalitas pelanggan pada Home Industri Produk Pakaian Sablon \& Bordir

4. Untuk mengetahui bagaimana pengaruh promosi terhadap loyalitas pelanggan pada Home Industri Produk Pakaian Sablon \& Bordir

5. Untuk mengetahui bagaimana pengaruh kepuasan pelanggan terhadap loyalitas pelanggan pada Home Industri Produk Pakaian Sablon \& Bordir

6. Untuk mengetahui bagaimana pengaruh langsung kualitas pelayanan dan promosi terhadap loyalitas

\section{B. KAJIAN LITERATUR}

\section{Kualitas Pelayanan}

Menurut Tjiptono (2011:59) "Kualitas pelayanan adalah tingkat keunggulan yang diharapkan dan pengendalian atas tingkat keunggulan tersebut untuk memenuhi keinginan pelanggan". "Menurut Zeithmal yang dikutip oleh Sudarso (2016:57) yang menyatakan bahwa Kualitas pelayanan merupakan manfaat yang dirasakan berdasarkan evaluasi konsumen atas interaksi dibandingkan dengan manfaat yang diharapkan sebelumnya".

"Dapat disimpulkan bahwa kualitas pelayanan adalah unsur yang saling berhubungan mengenai mutu yang dapat mempengaruhi kinerja dalam memenuhi harapan pelanggan dan dapat membangun kerja sama dalam jangka panjang dan saling dapat menguntungkan". Indikator yang digunakan untuk mengukur kualitas pelayanan menurut Tjiotono (2012:175) terdiri dari "Ketanggapan (responsiveness), Jaminan dan kepastian (Assurance), Bukti fisik (Tangible), Perhatian (Empathy), Keandalan (Realibility)".

\section{Promosi:}

"Lupiyoadi (2013:178) promosi merupakan salah satu variable dalam bauran pemasaran yang sangat penting oleh perusahaan dalam memasarkan produk atau jasa". Menurut Utami (2014:88) "promosi merupakan kegiatan yang mempengaruhi persepsi, sikap dan 
prilaku konsumen terhadap suatu toko ritel dengan segala penawarannya". Sedangkan menurut Giltosudarmo (2012:155) "mendefinisikan promosi sebagai kegiatan yang diajukan untuk memengaruhi konsumen agar mereka dapat menjadi kenal akan produk yang ditawarkan oleh perusahaan kepada mereka dan kemudian mereka menjadi senang lalu membeli produk tersebut". Kesimpulan yang dapat diambil dari definisi diatas bahwa "promosi adalah suatu cara dari sebuah perusahaan yang berperan untuk menginformasikan, membujuk dan mengingatkan calon konsumen akan produk perusahaan tersebut ciptakan, untuk menciptakan suatu permintaan dari konsumen agar bersedia menerima, membeli dan loyal pada produk yang ditawarkan". Sednaghkan indikator yang digunakan untuk mengukur promosi menurut Kotler dan Amstrong (2012:432) adalah "Advertising (periklanan), Sales promotion (promosi penjualan), Personal selling (penjualan perseorangan), Public relations (hubungan masyarakat), Direct marketing (penjualan langsung)".

\section{Kepuasan Pelanggan}

Lovelock dan Wirtz yang dikutip oleh Fandy Tjiptono (2016:74) "Kepuasan adalah suatu sikap yang diputuskan berdasarkan pengalaman yang didapatkan". Sangat dibutuhkan penelitian unutk membuktikan ada atau tidaknya harapan sebelumnya yang merupakan bagian terpenting dalam kepuasan. Sedangkan menurut Tjiptono (2015:146), "kepuasan pelanggan adalah perasaan senang atau kecewa seorang yang mucul setelah membandingkan antara persepsi terhadap kinerja (hasil) suatu produk dengan harapanharapannya". Sedangkan menurut jurnal Bachtiar (2011), "kepuasan konsumen merupakan perasaan positif konsumen yang berhubungan dengan produk / jasa selama menggunakan atau setelah menggunakan jasa atau produk. Jadi dapat disimpulkan dari beberapa pengertian tersebut menurut para ahli, bahwa "kepuasan konsumen adalah tingkat perasaan seseorang ketika menerima produk atau jasa yang ditawarkan serta membandingkan kinerja atas produk atau jasa yang diterima dengan harapan yang dimiliki". Sedangkan indikator yang digunakan untuk mengukur kepuasan menurut Lupiyoadi (2014:21) terdapat lima faktor indikator "Kualitas produk, Kualitas pelayanan, Emosional, Harga, Biaya".

\section{Loyalitas Pelanggan}

Tjiptono (2014:393) "mengemukakan bahwa Loyalitas pelanggan adalah komitmen pelanggan terhadap suatu merek, toko, atau pemasok, berdasarkan sikap yang sangat positif dan tercermin dalam pembelian ulang yang konsisten". Selanjutnya Pasuraman yang dikutip oleh Sangadji dan Shopiah (2013:104) mendefinisikan "bahwa Loyalitas pelanggan dalam konteks pemasaran jasa sebagai respon yang terkait erat dengan ikrar atau janji dengan memegang teguh komitmen yang mendasari kontinuitas relasi, dan biasanya tercermin dalam pembelian berkelanjutan dari penyedia jasa yang sama atas dasar dedikasi dan kendala pragmatis". Berdasarkan beberapa definisi yang dikemukakan para ahli di atas, maka peneliti sampai pada pemahaman bahwa loyalitas pelanggan adalah "komitmen pelanggan terhadap suatu merek, toko, ataupun pemasok yang tercermin atau ditunjukan dengan perilaku positif yaitu melakukan pembelian ulang yang berkelanjutan tanpa terpengaruh pemasaran yang dilakukan oleh pesaing". Indikator yang digunakna untuk mengukur loyalitas menurut Kotler \& Keller (2012:57) yaitu: "Pembelian ulang (Repeat Purchase), Merekomendasikan kepada pihak lain (Referalls), Tidak terpengaruh (Retention)".

\section{METODOLOGI PENELITIAN}

Jenis penelitian ini adalah penelitian kuantitatif yang dilakukan guna meneliti pada populasi atau sampel tertentu, pengumpulan data menggunakan instrumen penelitian, 
analisis data bersifat kuantitatif/statistik, dengan tujuan untuk menguji hipotesis yang telah ditetapkan. Sumber data dalam penelitian ini menggunakan data primer dimana data primer yang di gunakan terdiri dari Obervasi non partisipan dan kuisioner tertutup yang sudah di sediakan jawbananya oleh peneliti menggunakan skala Likert dan data skunder yang digunakan ialah refrensi dari buku-buku dan internet serta jurnal penelitia. Yang menjadi Populasi dalam penelitian ini adalah konsumen yang melakukan pemesanan pakaiain di Home Industri sebanyak 1.078 Konsumen, sedangkan jumlah sampel yang di gunakan dlama penelitian ini adalah 92 Konsuemn diperoleh dengan menggunakna Rumus Slovin dengan Erorr sebesar 10\%. Variabel penelitian dalam penelitia ini adalah Variabel Eksogen yang terdiri dari kualitas pelayanan dan promosi, sedangkan variabel endogen nya yaitu loyalitas dan varibale Intervening nya yaitu kepuasan. Analisis data dalam penelitian ini dengan menggunakan Uji Istrumen dimana dengan menguji Validitas relibilitas serta Uji Asumsiklasik dan Analisis Jalur. Opersional variabel penelitian dalam penelitian ini adalah:

\section{Tabel Opetasional Penelitian}

\begin{tabular}{|c|c|c|}
\hline Varaiabel & Indikator & Kuisioner \\
\hline \multirow{5}{*}{$\begin{array}{l}\text { Kualitas } \\
\text { Pelayanan }\end{array}$} & 1. Kehandalan & 1,2 \\
\hline & 2. Jaminan & 3,4 \\
\hline & 3. Bernviud & 5,6 \\
\hline & 4. Empati & 7,8 \\
\hline & 5. Ketangyapan & 9,10 \\
\hline \multirow[t]{5}{*}{ Promosi } & 1. Perikanan & 1,2 \\
\hline & 2. Promosi peniualan & 3,4 \\
\hline & 3. Penjualan persecorangan & 5,6 \\
\hline & 4. Hubungan massarakat & 7,8 \\
\hline & 5. Penjualan langsung & 9,10 \\
\hline Kepuasan & 1. Kualitas produluk & 1,2 \\
\hline \multirow[t]{4}{*}{ Konsumen } & 2. Kualitas pelaranan & 3,4 \\
\hline & 3. Emosional & 5,6 \\
\hline & 4. Harga & 7,8 \\
\hline & 5. Biara & 9,10 \\
\hline \multirow[t]{3}{*}{ Lojalitas } & 1. Pembelian ulang & 1,2 \\
\hline & $\begin{array}{l}\text { 2. Merekomendasi phak } \\
\text { lain }\end{array}$ & 3,4 \\
\hline & 3. Tidak terpengaruh & 5,6 \\
\hline
\end{tabular}

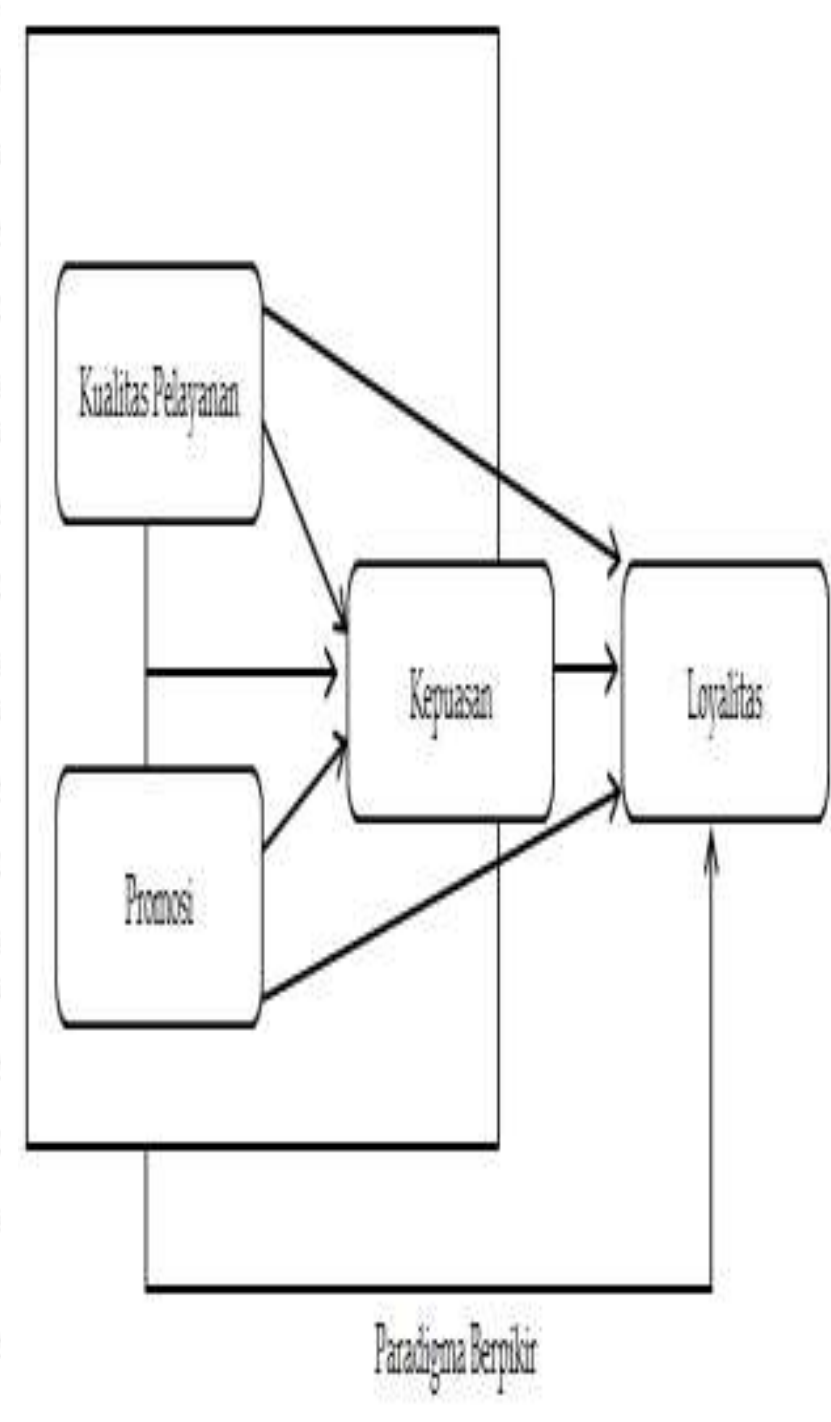


ISSN NO. (PRINT) 2598-0823, (ONLINE) 2598-2893

D. HASIL DAN PEMBAHASAN

Hasil Uji Instrument Penelitian

Uji Validitas

Tabel Uji Rangkuman Uji Validitas

\begin{tabular}{|c|c|c|c|c|c|}
\hline No & K. Pelayanan & Promosi & Kepuasan & Loyalitas & Keputusan \\
\hline 1 & 0.636 & 0.683 & 0.495 & 0.704 & Valid \\
\hline 2 & 0.679 & 0.631 & 0.732 & 0.82 & Valid \\
\hline 3 & 0.643 & 0.554 & 0.585 & 0.554 & Valid \\
\hline 4 & 0.644 & 0.725 & 0.569 & 0.776 & Valid \\
\hline 5 & 0.491 & 0.558 & 0.688 & 0.732 & Valid \\
\hline 6 & 0.57 & 0.401 & 0.744 & 0.818 & Valid \\
\hline 7 & 0.517 & 0.677 & 0.632 & - & Valid \\
\hline 8 & 0.757 & 0.609 & 0.661 & - & Valid \\
\hline 9 & 0.658 & 0.596 & 0.697 & - & Valid \\
\hline 10 & 0.793 & 0.642 & 0.689 & - & Valid \\
\hline
\end{tabular}

Tabel Validitas mengindikasikan semua instrumen dari semua vatiabel dinyatakan valid dengan kriteria R hitung > 0,30, hal ini sejalan dengan Teori Sugiyono (2017:182).

\section{Uji Relibilitas}

Tabel Rangkuman Uji Relibilitas

\begin{tabular}{|c|l|c|c|l|}
\hline No. & \multicolumn{1}{|c|}{ Variabel } & Chronbach Alpha & $\begin{array}{c}\text { Standar Chronbach } \\
\text { Alpha }\end{array}$ & Keputusan \\
\hline 1 & Kualitas Pelayanan & 0,840 & 0,60 & Reliabel \\
\hline 2 & Promosi & 0,813 & 0,60 & Reliabel \\
\hline 3 & Kepuasan & 0,846 & 0,60 & Reliabel \\
\hline 3 & Loyalitas & 0,830 & 0,60 & Reliabel \\
\hline
\end{tabular}

Semua variabel dalam studi ini menunjukkan nilai coeficien Alpha lebih besar dari Chronbach Alpha 0,60. Hal in isejalan dengan teori dari Sugiyono (2017:184) yang mengatakan bahwa syarat minimal uji realibilitas adalah jika nilai Rca nya 0,60. 


\section{Uji Asumsi Klasik Uji Normalitas}

\section{Tabel Rangkuman}

Hasil Uji Normalitas Dengan Kolmogorov-Smimov Test

\begin{tabular}{|l|l|l|}
\hline & $\begin{array}{c}\text { Unstandardized } \\
\text { Residual Pers.1 }\end{array}$ & $\begin{array}{c}\text { Unstandardized } \\
\text { Residual Pers.2 }\end{array}$ \\
\hline Asymp.Sig (2 Tailed) & 0.694 & 0,621 \\
\hline
\end{tabular}

Pada tabel di atas, diperoleh nilai Asymp. Sig. tersebut lebih besar dari nilai $\alpha=0,050$. Dengan demikian maka asumsi distribusi persamaan pada uji ini adalah normal

\section{Uji Multikolinieritas}

\begin{tabular}{|l|c|c|c|c|}
\multicolumn{5}{c}{ Tabel Rangkuman } \\
\hline \multirow{2}{*}{ Model } & Persamil Pengujian Multikolinearitas Dengan Collinearity Statistic \\
\cline { 2 - 5 } & Tolerance & VIF & Tolerance & VIF \\
\hline Pelayanan & 0,464 & 2,157 & 0,453 & 2,207 \\
\hline Promosi & 0,464 & 2,157 & 0,382 & 2,619 \\
\hline Kepuasan & & & 0,577 & 1,733 \\
\hline
\end{tabular}

pada tabel di atas diperoleh nilai tolerance masing-masing variabel bebas lebih dari 0,10 , dan nilai Variance Inflation Factor (VIF) kedua variabel $<10,0$. Dengan demikian model regresi ini tidak ada multikolinearitas.

\section{Analisis Karakteristik Responden}

Berdasarkan jenis kelamin maka mayoritas responden adalah perempuan, dikarenakan biasayanya perempan yang yang membeli atau memesan baju Sablon di Angel Clothing. Berdasakn usia maka mayotitas Usia 21-26 Th, karena usia tersebut masa Remaja sesuai dengan Angel Cloth yag banyak menyediakan jasa Sablon baju remaja, sedangakn berdasakan pendapatan responden maka mayoritas pendapatan responden adala Lainya sebnayak 42 atau $45,56 \%$ dimana kabanyakan responden tidak mau memberitahu tentang penghasilan yang di peroleh nya.

\section{Analisis Deskriptif Variabel Penelitian \\ Kualitas Pelayanan}

Berdasarkan jawaban dari responden pada variabel Kualitas Pelayanan diperoleh rata-rata skor 3,49 dimana angka tersebut berada pada rentang skala 3,40-4,19 dengan kriteria baik, dan dibuktikan dari skor tertinggi pada pernyataan no 4 yaitu sebesar 4,01 dimana Karyawan pada Angels Clothing Sopan dan Ramah, hal ini membuktikan bahwa kualitas pelayanan sudah baik dan sesuai dengan SOP

\section{Promosi}

Berdasarkan tanggapan responden maka variabel Promosi didapat hasil rata-rata skor 3,56 nilai tersebut berada pada rentang skala 3,40-4,19 dengan kriteria baik, dan dilihat dari skor tertinggi pada pernyataan no 6 yaitu sebesar 4,09, dimana penjualan yang dilakukan secara langsung dengan mempresentasaikan produk yang ada dengan memberikan contoh produk secara langsung dapat lebih menarik konsumen yang ingin 
membeli produk di Angle Cloth, maka dari itu sebaik nya Angel Cloth mempertahan kan stratgi ini.

\section{Kepuasan Pelanggan}

Untuk jawaban responden pada variabel Kepuasan didapat hasil rata-rata skor 3,57 dimana angka tersebut berada pada rentang skala 3,40-4,19 dengan kriteria baik, dan dilihat dari skor tertinggi pada pernyataan no 9 dengan skor 3,96, dimana Konsumen yang ingin mebeli dalam jumlah banyak maka "Tidak perlu mengeluarkan biaya tambahan produk yang sudah jadi”, hal ini memudahkan dan memberikan keungtungan bagi konsumen.

\section{Loyalitas}

Tanggapan responden variabel Loyalitas beragam, diperoleh rata-rata skor sebesar 3,39 termasuk pada rentang skala 2,60 - 3,39 dengan kriteria Cukup Baik, dan dibuktikan dari skor tertinggi pada pernyataan no 5 yaitu sebesar 3,76 dimana Konsumen yang merasa puas atas produknya tidak akan terpengaruh dengan produk lainnya, hal ini membuktikan bahwa produk yang di hasil kan oleh Angel Cloth sudah baik dan sesuai dengan keinginan konsumen.

\section{Analisis Data}

\section{Uji Statistik Parsial}

Tabel Rangkuman Hasil Uji Hipotesis Parsial

\begin{tabular}{|l|c|c|c|c|c|}
\hline \multicolumn{7}{|c|}{ Kulitas Pelayanan, Promosi dan Kepuasan Terhadap Loyalitas } \\
\hline \multicolumn{1}{|c|}{ Variabel } & $\mathrm{t}$ & Sig & $\mathrm{t}$ tabel & $\mathrm{t}$ sig & Ket \\
\hline Kualitas Pelayanan & 3.016 & .003 & 1.987 & 0.005 & $\mathrm{t}$ hit $>\mathrm{t}$ tab dan sig $<\mathrm{t}$ sig Ha diterima \\
\hline Promosi & 3.459 & .001 & 1.987 & 0.005 & $\mathrm{t}$ hit $>\mathrm{t}$ tab dan sig $<\mathrm{t}$ sig Ha diterima \\
\hline Kepuasan & 4.624 & .000 & 1.987 & 0.005 & $\mathrm{t}$ hit $>\mathrm{t}$ tab dan sig $<\mathrm{t}$ sig Ha diterima \\
\hline \multicolumn{7}{|c|}{ Kualitras Pelayanan dan Promosi Terhadap Kepuasan } \\
\hline Kualitas Pelayanan & 3.430 & .002 & 1.987 & 0.005 & $\mathrm{t}$ hit $>\mathrm{t}$ tab dan sig $<\mathrm{t}$ sig Ha diterima \\
\hline Promosi & 4.366 & .000 & 1.987 & 0.005 & $\mathrm{t}$ hit $>\mathrm{t}$ tab dan sig $<\mathrm{t}$ sig Ha diterima \\
\hline
\end{tabular}

Berdasarkan tabel tersebut maka uji Hipotesis secara parsial pada masing-masing variabel memiliki pengaruh karena nilai $t_{\text {hit }}>t_{\text {tab }}$ dan $t_{\text {sig }}<$ sig, sehingga Ha diterima.

\section{Uji Statistik Simultan}

\section{Tabel Rangkuman Hasil Uji Hipotesis Simultan}

\begin{tabular}{|c|c|c|c|c|}
\hline \multicolumn{6}{|c|}{ Kulitas Pelayanan, Promosi dan Kepuasan Terhadap Loyalitas } \\
\hline F & Sig & F tabel & F sig & Ket \\
\hline 66,246 & .000 & 3.099 & 0.000 & F hit $>$ F tab dan F sig < sig Ha \\
\hline \multicolumn{6}{|c|}{ Kualitras Pelayanan dan Promosi Terhadap Kepuasan } \\
\hline 32.637 & .000 & 3.099 & 0.000 & F hit $>$ F tab dan F sig < sig Ha \\
\hline
\end{tabular}


Berdasarkan tabel tersebut maka uji Hipotesis secara Simultan pada masing-masing variabel memiliki pengaruh karena nilai $F$ hit $>F$ tab dan $F$ sig $<$ sig, sehingga Ha diterima.

\section{Uji Dterminasi}

Tabel Rangkuman Hasil Uji Koefisien Determinasi

\begin{tabular}{|c|c|c|}
\hline \multicolumn{3}{|c|}{ Kulitas Pelayanan, Promosi dan Kepuasan Terhadap Loyalitas } \\
\hline$R$ & $R$ & Adjusted R Square \\
\hline .833 & .693 & .683 \\
\hline Kualitras Pelayanan dan Promosi Terhadap Kepuasan \\
\hline .650 & .423 & .410 \\
\hline
\end{tabular}

Berdasarkan tabel diatas diketahui nilai koefisien korelasi $R$ sebesar 0,833 , hal ini menginformasikan bahwa adanya hubungan yang Sangat Kuat $(0,80-1,00)$ Sugiyono (2013:250), antara variable independen dengan dependen. Sedangkan nila koefisien determinasi $R 2$ yaitu 0,693 yang menjelaskan bahwa variable independen berkontribusi mempengaruhi variable dependen sebesar $69,3 \%$ dan sisanya $30,7 \%$ dijelaskan oleh variable lain diluar penelitian yang sedang dijalankan ini.

Jika dilihat pada tabel diatas maka nilai koefisien korelasi $R$ sebesar 0,650 , hal tersebut menunjukan ada nya hubungan yang Kuat (0,60-0,799), Sugiyono (2013:250) antara variable independen dengan dependen. Sedangkan nila koefisien determinasi R2 yaitu 0,554 yang menjelaskan bahwa variable independen berkontribusi mempengaruhi variable dependen sebesar $55,4 \%$ dan sisanya $44,6 \%$ dijelaskan oleh variable lain diluar penelitian yang sedang dijalankan ini

\section{Uji Analisis Jalur}

Untuk menguji pengaruh variable intervening digunakan meotde analisis jalur yang merupakan perluasan dari analisis regresi linier berganda atau analisis jalur adalah penggunaan analisis regresi untuk menaksir hubungan kausalitas antar variable (modecausal) yang telah ditetapkan sebelumnya berdasarkan teori dan menentukan pola hubungan antara tiga atau lebih variable dan tidak dapat digunakan untuk mengkonfirmasi atau menolak hipotesis (Ghazali, 2013:249).

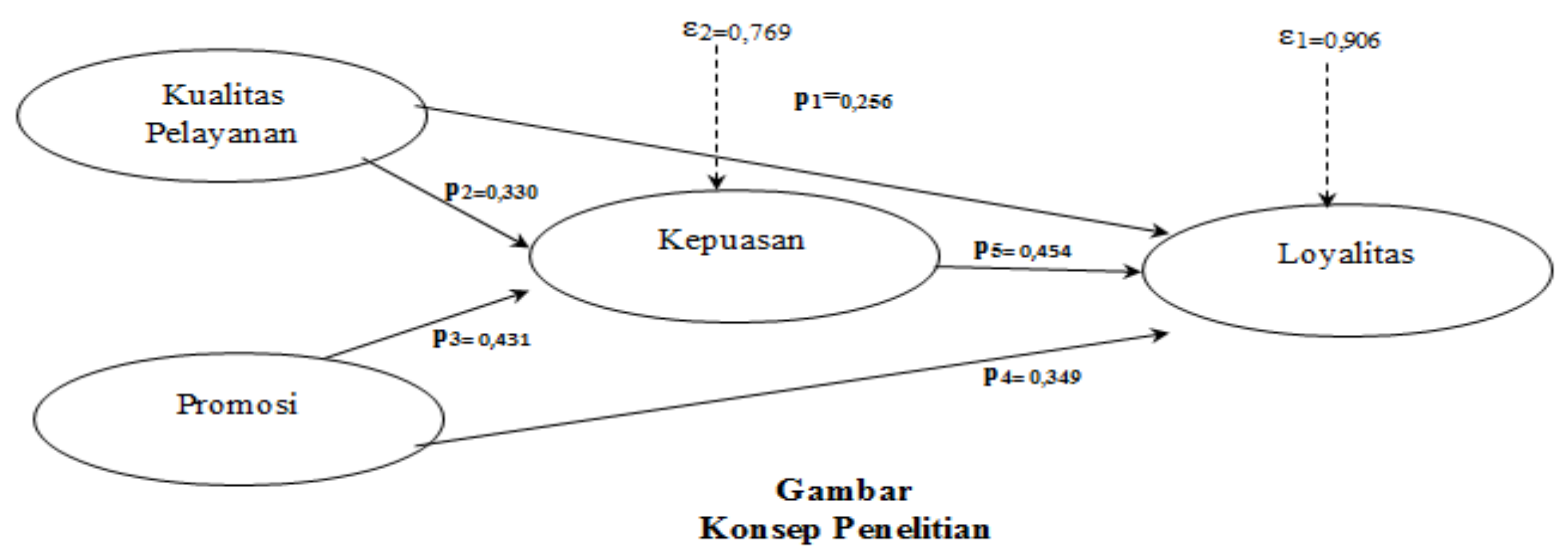


ISSN NO. (PRINT) 2598-0823, (ONLINE) 2598-2893

Tabel Hasil Uji T test

Kualitas Pelayanan, Promosi dan Kepuasan-Loyalitas

Coefficients $^{a}$

\begin{tabular}{|c|c|c|c|c|c|c|}
\hline \multirow{2}{*}{\multicolumn{2}{|c|}{ Model }} & \multicolumn{2}{|c|}{ Unstandardized Coefficients } & \multirow{2}{*}{$\begin{array}{c}\text { Standardized } \\
\text { Coefficients }\end{array}$} & \multirow[b]{2}{*}{ t } & \multirow[b]{2}{*}{ Sig. } \\
\hline & & $\mathrm{B}$ & Std. Error & & & \\
\hline \multirow[t]{4}{*}{1} & (Constant) & 5.596 & 2.497 & & 2.242 & .028 \\
\hline & Pelayanan & .256 & .085 & .265 & 3.016 & .003 \\
\hline & Promosi & .349 & .101 & .331 & 3.459 & .001 \\
\hline & Kepuasan & .454 & .098 & .360 & 4.624 & .000 \\
\hline
\end{tabular}

a. Dependent Variable: Loyalitas

Tabel Hasil Uji T test

Kualitas Pelayanan, Promosi -Kepuasan

Coefficients $^{\mathrm{a}}$

\begin{tabular}{|ll|r|r|r|r|r|}
\hline \multirow{2}{*}{ Model } & \multicolumn{2}{|c|}{ Unstandardized Coefficients } & \multicolumn{2}{c|}{$\begin{array}{c}\text { Standardized } \\
\text { Coefficients }\end{array}$} & & \\
\cline { 3 - 5 } & \multicolumn{1}{|c|}{$\mathrm{B}$} & Std. Error & \multicolumn{1}{c|}{ Beta } & \multicolumn{1}{c|}{ Sig. } \\
\hline 1 & (Constant) & 2.516 & .694 & & 1.191 & .849 \\
& Kualitas Pelayanan & .330 & .906 & .469 & 3.430 & .002 \\
& Promosi & .431 & .099 & .516 & 4.366 & .000 \\
\hline
\end{tabular}

a. Dependent Variable: Kepuasan

Tabel Hasil Uji Koefisien Determinasi

Model Summary ${ }^{\mathrm{b}}$

\begin{tabular}{|l|l|l|r|r|}
\hline Model & $\mathrm{R}$ & R Square & $\begin{array}{c}\text { Adjusted R } \\
\text { Square }\end{array}$ & $\begin{array}{c}\text { Std. Error of } \\
\text { the Estimate }\end{array}$ \\
\hline 1 & $.833^{\mathrm{a}}$ & .693 & .683 & 2.521 \\
\hline
\end{tabular}

a. Predictors: (Constant), Kepuasan, Pelayanan, Promosi

b. Dependent Variable: Loyalitas

$$
\begin{gathered}
e 1=\sqrt{1-r 2} \\
\mathrm{e} 1=\sqrt{1-0,639^{2}} \\
\mathrm{e} 1=0,769
\end{gathered}
$$


Tabel Hasil Uji Koefisien Determinasi

Model Summary ${ }^{\mathrm{b}}$

\begin{tabular}{|l|c|r|r|r|}
\hline Model & $\mathrm{R}$ & R Square & $\begin{array}{c}\text { Adjusted R } \\
\text { Square }\end{array}$ & $\begin{array}{c}\text { Std. Error of } \\
\text { the Estimate }\end{array}$ \\
\hline 1 & $.650^{\mathrm{a}}$ & .423 & .410 & 2.720 \\
\hline
\end{tabular}

a. Predictors: (Constant), Promosi, Kualitas Pelayanan

b. Dependent Variable: Kepuasan

$$
\begin{gathered}
e 2=\sqrt{1-r 2} \\
\mathrm{e} 2=\sqrt{1-0,423^{2}} \\
\mathrm{e} 2=0,906
\end{gathered}
$$

Dari tabel dan rumus diatas dikethaui pengaruh langsung atau tidak langsung serta pengaruh total dari penelitian ini yaitu:

1) Pengaruh langsung Kualitas Pelayanan terhadap Loyalitas $\left(p_{1}\right)=0,256$

2) Pengaruh tidak langsung Kualitas Pelayanan terhadap Loyalitas $p_{2} \times p_{5}=0,330 \times 0,454=0,14982$

Maka pengaruh tidaklangsung antara $X_{1}$ ke $Y$ sebesar 0,14982

3) Pengaruh total kepemimpian terhadap Loyalitas

Pengaruh langsung + pengaruh tidak langsung

$=p_{1}+\left(p_{2} \times p_{5}\right)=0,256 \times 0,14982=0,03835392$

4) Pengaruh total Promosi terhadap Loyalitas $\left(p_{4}\right)=0,439$

5) Pengaruh tidak langsung Promosi terhadap Loyalitas

$p_{3} \times p_{5}=0,431 \times 0,454=0,195674$

Mka pengaruh anatara $X_{2}$ ke $Y$ Sebesar 0,195674

6) Pengaruh total Promosi terhadap Loyalitas

Pengaruh langsung + pengaruh tidak langsung $=$

$=\mathrm{p}_{4}+\left(\mathrm{p}_{3} \times \mathrm{p}_{5}\right)$

$=0,439+0,195674=0,634674$

Maka pengaruh total $X_{2}$ ke $Y$ sebesar 0,634674

Untuk mengetahui tingkat mediasi variabel kepuasan terhadap Loyalitas dan Promosi terhadap Loyalitas maka standar error dari koefisien indirect effect dpat dinyatakana:

1. $S p 2 s p 5=\sqrt{p 5^{2} s p 2^{2}+p 2^{2} s p 5^{2}+s p 2^{2} s p 5^{2}}$

$$
\begin{aligned}
& \operatorname{Sp} 2 \operatorname{Sp} 5=\sqrt{(0,454)^{2} \cdot(0,524)^{2}+(0,330)^{2} \cdot(0,098)^{2}+(0,906)^{2} \cdot(0,098)^{2}} \\
& \operatorname{Sp} 2 \operatorname{Sp} 5=\sqrt{0,065527612} \\
& \operatorname{Sp} 2 \operatorname{Sp} 5=0,255983617
\end{aligned}
$$

2. $\quad s p 3 p 5=\sqrt{p 5^{2} s p 3^{2}+p 3^{2} s p 5^{2}+s p 3^{2} s p 5^{2}}$

$$
\begin{aligned}
& s p 3 p 5=\sqrt{(0454)^{2} \cdot(0,099)^{2}+(0,431)^{2} \cdot(0,098)^{2}+(0,099)^{2} \cdot(0,098)^{2}} \\
& s p 3 p 5=\sqrt{0,0038983208040} \\
& s p 3 p 5=0,0624365342087467
\end{aligned}
$$


1) $\mathrm{t} 1=\frac{\mathrm{p} 2 \mathrm{p} 5}{S p 2 p 5}=\frac{0,330 * 0454}{0,906 * 0,454}=\frac{0,14982}{0,048124}=3,113$
2) $\mathrm{t} 2=\frac{\mathrm{p} 3 \mathrm{p} 5}{S p 3 p 5}=\frac{0,431 * 0,454}{0,099 * 0,454}=\frac{0,1954674}{0,044946}=4,354$

Dengan melihat semua semua pengukuran ditas maka sdapat ditarik kesimpulan sebagai berikut:

1) Karena t hitung sebesar 3,113 dan t-tabel 1,987 dengan niai signifikansi 0,05 , maka dapat disimpulkan bahwa koefisein mediasi sebesar 0,03835392 signifikan yang berarti kepuasan dapat menjadi mediator dalam pengaruh Kualitas Pelayananan terhadap Loyalitas .

2) Karena thitug sebesar 4,354 dan t tabel 1,987 denga nilai signfikansi 0,05 , maka dapat disimpulkan koefisien mediasi sebesar 0,634674 yang berati kepuasan dapat menjadi mediator dalam pengaruh Promosi terhadap Loyalitas .

\section{Pembahasan}

\section{Kualitas Pelayanan}

1. Uji validitas menunjukan bahwa instrumen kusioner dari no 1-10 dinyatakan valid karena pada instrument kuisioner no 1 diperoleh nilai $r_{\text {hit }}(0,636)>r_{\text {tabel }}(0,300)$ hal ini sejalan dengan teori Sugiyono (2017:182).

2. Uji reliabilitas menunjukan nilai $r_{\text {ca }}(0,839)>r_{\text {tabel }}(0,600)$ yang sejalan dengan teori Sugiyono (2017:184).

3. Kualitas pelayanan dikatak sudah baik dan dibuktikan dengan Karyawan pada Angels Clothing Sopan dan Ramah, hal ini membuktikan bahwa kualitas pelayanan sudah baik dan sesuai dengan SOP, Namun disamping itu masih terdapat skore rendah dimana masih terdapat responden yang menyatakan tidak setuju dikarenakan Karyawan tidak cepat semua nya bisa menangani keluhan dengan baik, maka dari itu sebaiknya perusahaan memberikan perhatian yang lebih kepada karyawan agar karyawan juga dapat bekerja dengan baik.

4. Hasil uji hipotesis (Kualitas Pelayanan berpengaruh signifikan terhadap Kepuasan) Variabel Kualitas Pelayanan memiliki nilai standardized coefficients sebesar 0,469 dan tingkat significant sebesar 0,002 pada koefisien alpha 5\%. Dari hasil tersebut menunjukan bahwa tingkat significant kurang dari $5 \%$ atau 0,002 $<0,05$. Maka artinya terdapat pengaruh signifikan antara Kualitas Pelayanan $\left(\mathrm{X}_{1}\right)$ terhadap kepuasan (Z). Yang dapat ditarik pengertian tiap kenaiakan variabel Kualitas Pelayanan $1 \%$ maka akan menaikan 46,9\% tingkat kepuasan. Kesimpulan ini sependapat dengan penelitian yang dilakukan Noviati (2018).

\section{Promosi}

1. Uji validitas menunjukan bahwa instrumen kusioner dari no 1-10 dinyatakan valid karena pada instrument kuisioner no 1 diperoleh nilai $r_{\text {hit }}(0,683)>r_{\text {tabel }}(0,300)$ hal ini sejalan dengan teori Sugiyono (2017:182).

2. Uji reliabilitas menunjukan nilai $r_{c a}(0,813)>r_{\text {tabel }}(0,600)$ yang sejalan dengan teori Sugiyono (2017:184).

3. Variabel Promosi Sudah baik dimana penjualan yang dilakukan secara langsung dengan mempresentasaikan produk yang ada dengan memberikan contoh produk secara langsung dapat lebih menarik konsumen yang ingin membeli produk di Angle 
Cloth, maka dari itu sebaik nya Angel Cloth mempertahan kan stratgi ini. Namun disamping itu masih terdapat skor rendah dan dari hasil obervasi dilapangan masih terdapat kegiatan yang dilakukan oleh masyrakat yang tidak disponsori oleh Angel Cloth, maka dari sebaiknya Angle Cloth lebih dekat lagi dengan masyrakat sehingga masyrakat lebih percaya dengan Angel Cloth, seperti menjadi Sponsor Event untuk pembuatan Baju Sepak bola karena sebentar lagi akan di adakann acara 17'an oleh masyrakat sekitar.

4. Hasil uji hipotesis (Promosi berpengaruh signifikan terhadap kepuasan)

Variabel Promosi memiliki nilai standardized coefficients sebesar 0,516 dan tingkat significant sebesar 0,000 pada koefisien alpha 5\%. Dari hasil tersebut menunjukan bahwa tingkat significant kurang dari $5 \%$ atau $0,000<0,05$. Maka artinya terdapaat pengaruh signifikan antara Promosi $\left(\mathrm{X}_{2}\right)$ terhadap kepuasan $(\mathrm{Z})$. Yang dapat ditarik pengertian tiap kenaiakan variabel Promosi $1 \%$ maka akan menaikan 51,6\% tingkat Kepuasan. Kesimpulan ini sependapat dengan penelitian yang dilakukan oleh Hadira (2019).

\section{Kepuasan}

1. Uji validitas menunjukan bahwa instrumen kusioner dari no 1-10 dinyatakan valid karena pada instrument kuisioner no 1 diperoleh nilai $r_{\text {hit }}(0,495)>r_{\text {tabel }}(0,300)$ hal ini sejalan dengan teori Sugiyono (2017:182).

2. Uji reliabilitas menunjukan nilai $r_{\mathrm{ca}}(0,846)>r_{\text {tabel }}(0,600)$ yang sejalan dengan teori Sugiyono (2017:184).

3. Variabel Kepuasan dikatakan sudah baik, dimana Konsumen yang ingin membeli dalam jumlah banyak Tidak perlu mengeluarkan biaya tambahan produk yang sudah jadi, hal ini memudahkan dan memberikan keungtungan bagi konsumen. Namun selain itu masih terdapat konsumen yang kurang puas karena masih kurang nya keperulian sosial karyawan terhadap konsumen, maka dari itu sebaiknya Angel Cloth memberikan masukan atau brifieng kepada karyawan sebelum memulai kerja dengan meberikan masukan tentang konsumen serta masalah-masalah yang terjadi berkaitan dengan Produk dari Angel Cloth, sehingga karyawan bisa lebih perduli.

4. Hasil uji hipotesis (kepuasan berpengaruh signifikan terhadap Loyalitas )

Variabel kepuasan memiliki nilai standardized coefficients 0,360 dan tingkat significants 0,000 pada koefisien alpha sebesar $5 \%$. Dengan hasil tersebut menunjukan bahwa tingkat signficant kurang dari 5\% atau 0,000 $<0,05$. Yang artinya terdapat pengaruh signifikan antara kepuasan (Z) terhadap Loyalitas (Y). Yang dapat ditarik kesimpulan tiap kenaiakn $1 \%$ variabel kepuasan maka akan menaikan $36,0 \%$ Loyalitas . Kesimpulan ini sependapat dengan penelitian yang dilakukan oleh Nurmin Arianto (2018).

\section{Loyalitas}

1. Uji validitas menunjukan bahwa instrumen kusioner dari no 1-10 dinyatakan valid karena pada instrument kuisioner no 1 diperoleh nilai $r_{\text {hit }}(0,704)>r_{\text {tabel }}(0,300)$ hal ini sejalan dengan teori Sugiyono (2017:182).

2. Uji reliabilitas menunjukan nilai $r_{c a}(0,769)>r_{\text {tabel }}(0,600)$ yang sejalan dengan teori Sugiyono (2017:184).

3. Variabel Loyalitas dikatakan sudah Cukup Baik, Konsumen yang merasa puas atas produknya tidak akan terpengaruh dengan produk lainnya, hal ini membuktikan bahwa produk yang di hasil kan oleh Angel Cloth sudah baik dan sesuai dengan keinginan konsumen, Namun disisilain masih terdapat skor rendah sebaik nya karyawan bisa lebih membujuk konsumen agar bisa merekomendasikan Angel Cloth kepada 
konsumen lain nya misalnya dengan memberikan penjelasan yang baik, memberikan bonus jika bisa mengajak konsumen menggunakan produk dari Angel Cloth.

4. Hasil uji hipotesis (Promosi berpengaruh signifikan terhadap Loyalitas)

Variabel Promosi memiliki nilai standardized coefficients sebesar 0,331 dan tingkat significant sebesar 0,001 pada koefisien alpha 5\%. Dari hasil tersebut menunjukan bahwa tingkat significant kurang dari $5 \%$ atau 0,001 $<0,05$. Maka artinya terdapaat pengaruh signifikan antara Promosi $\left(\mathrm{X}_{2}\right)$ terhadap Loyalitas $(\mathrm{Y})$. Yang dapat ditarik pengertian tiap kenaiakan variabel Promosi $1 \%$ maka akan menaikan 33,1\% tingkat Loyalitas. Kesimpulan ini sependapat dengan penelitian Sarjita (2018).

5. Hasil uji hipotesis (Kualitas Pelayanan berpengaruh signifikan terhadap Loyalitas)

Variabel Kualitas Pelayanan memiliki nilai standardized coefficients sebesar 0,265 dan tingkat significant sebesar 0,003 pada koefisien alpha 5\%. Dari hasil tersebut menunjukan bahwa tingkat significant kurang dari $5 \%$ atau $0,003<0,05$. Maka artinya terdpaat pengaruh signifikan antara Kualitas Pelayanan $\left(\mathrm{X}_{1}\right)$ terhadap Loyalitas $(\mathrm{Y})$. Yang dapat ditarikpengertian tiapkenaiakan variabel Kualitas Pelayanan $1 \%$ maka akan menaikan $26,5 \%$ tingkat Loyalitas . Hal ini sejalan dengan penelitian yang dilakukan oleh Sarjita (2018), Nurmin Arianto (2018), Novianti (2018)

\section{Pengujian Hasil Path Analisis}

Variabel kepuasan dengan dimediasi mempunyai nilai t hitung sebesar 3,113 lebih besar dari t tabel yaitu 1,987 dengan tingkat signifikansi 5\%, maka dapat disimpulkan bahwa koefisien mediasi sebesar 0,03835392 seignifikan yang berarti ada pengaruh memediasi. Yang berati kepuasan dapat memediasi pengaruh Kualitas Pelayanan terhadap Loyalitas dengan pengaruh positif dan signifikan.

Variabel Promosi dengan dimediasi kepuasan mempunyai nilai t hitung sebesar 4,354 lebih besar dari t tabel 1,987 dengan tingkat singfikansi 5\% maka dapat disimpulkan bahwa koefisien mediasi sebesar 0,634674 signifkana yang berarti adal pengaruh mediasi. Yang berarti kepuasan dapat memediasi pengaruh Promosi terhadap Loyalitas dengan pengaruh yang positif dan signfikan. Untuk mempemudah dalam membaca kesimpulan diatas maka penulis membuat nya dalam bentuk tabel, berkut ini:

\begin{tabular}{|c|c|c|c|}
\hline No & Hipotesis & Hasil & Kesim \\
\hline 1 & $\begin{array}{l}\text { Terdapat pengaruh yang signifikan } \\
\text { antara Kualitas Pelayanan terhadap } \\
\text { kepuasan }\end{array}$ & $\begin{array}{lcr}\text { Kualitas } & \text { Pelayanan } & \text { memiliki } \\
\text { pengaruh } & \text { yang } & \text { signifikan } \\
\text { terhadap kepuasan } & \end{array}$ & Diterima \\
\hline 2 & $\begin{array}{l}\text { Terdapat pengaruh yang signfikan } \\
\text { antara Promosi terhadapa kepuasan }\end{array}$ & $\begin{array}{l}\text { Promosi memiliki pengaruh yang } \\
\text { signifikan terhadap kepuasan }\end{array}$ & Diterima \\
\hline 3 & $\begin{array}{l}\text { Terdapat pengaruh yang siginifikan } \\
\text { antara Kualitas Pelayanan terhadap } \\
\text { Loyalitas }\end{array}$ & $\begin{array}{lrr}\text { Kualitas } & \text { Pelayanan } & \text { memiliki } \\
\text { pengaruh yang } & \text { signifikan } \\
\text { terhadap Loyalitas } & \end{array}$ & Diterima \\
\hline 4 & $\begin{array}{l}\text { Terdapat pengaruh yang sigfinikan } \\
\text { antara Promosi terhadap Loyalitas }\end{array}$ & $\begin{array}{l}\text { Promosi memiliki pengaruh yang } \\
\text { sigifikan terhadap Loyalitas }\end{array}$ & Diterima \\
\hline 5 & $\begin{array}{l}\text { Terdapat pengaruh yang signifikan } \\
\text { antara kepuasan terhadap Loyalitas }\end{array}$ & $\begin{array}{l}\text { Kepuasan memiliki pengaruh } \\
\text { yang signfikan terhadap Loyalitas }\end{array}$ & Diterima \\
\hline
\end{tabular}




\section{E. KESIMPULAN}

Berisi simpulan dengan perampatan yang meluas dari pembahasan hasil penelitian yang dituliskan dengan singkat dan jelas, menunjukkan kejelasan sumbangan temuan, pencetusan teori baru dan kemungkinan pengembangan penelitian yang bisa dilakukan kedepannya. Implikasi teoritis dan praktis, keterbatasan dan saran penelitian juga dituliskan dalam paragraf mengalir.

Berdasarkan hasil penelitian maka diperoleh kesimpulan:

1. Dari hasil pengujian $t$ test menunjukan Kualitas Pelayanan berpengaruh positif dan sigifikan terhadap kepuasan.

2. Dari hasil pengujian $t$ test menunjukan Promosi berpengaruh positif dan sigifikan terhadap kepuasan.

3. Dari hasil pengujian t test menunjukan Kualitas Pelayanan berpengaruh positif dan sigifikan terhadap Loyalitas .

4. Dari hasil pengujian t test menunjukan Promosi berpengaruh positif dan sigifikan terhadap Loyalitas .

5. Dari hasil pengujian $t$ test menunjukan kepuasan berpengaruh positif dan sigifikan terhadap Loyalitas.

6. Dengan melakaukan pengujian menggunakan analisis jalur (path analisi) menunjukan bahwa Kualitas Pelayanan berpengaruh langsung psositif dan signfikan terhadap Loyalitas dengan dimediasi oleh kepuasan. Dan hasil penguj dengan menggunakan analisis jalur (path analisis) menunjukan bahwa promosi berpengaruh lansung positif dn signfiikan terhadap Loyalitas dengan dimediasi oleh kepuasan.

\section{Saran}

Berisi keterbatasan penelitian dan saran yang dapat diberikan untuk penelitian selanjutnya.

1. Dari hasil penelitian maka sebaiknya perusahaan memberikan perhatian yang lebih kepada karyawan agar karyawan juga dapat bekerja dengan baik.

2. Sebaiknya Angle Cloth lebih dekat lagi dengan masyrakat sehingga masyrakat lebih percaya dengan Angel Cloth, seperti menjadi Sponsor Event untuk pembuatan Baju Sepak bola karena sebentar lagi akan di adakann acara 17'an oleh masyrakat sekita.

3. Angel Cloth memberikan masukan atau brifieng kepada karyawan sebelum memulai kerja dengan meberikan masukan tentang konsumen serta masalah-masalah yang terjadi berkaitan dengan Produk dari Angel Cloth, sehingga karyawan bisa lebih perduli.

4. Sebaik nya karyawan bisa lebih membujuk konsumen agar bisa merekomendasikan Angel Cloth kepada konsumen lain nya misalnya dengan memberikan penjelasan yang baik, memberikan bonus jika bisa mengajak konsumen menggunakan produk dari Angel Cloth.

5. Bagi peneliti selanjut nya sebaiknya menambahkan jumal sampel karena keterbatasan waktu maka jumalh sampel yang di gunakan dalam penelitian relative kecil. 


\section{DAFTAR PUSTAKA}

Arianto, N. (2016). Pengaruh Citra Merek, Promosi dan Distribusi Terhadap Loyalitas Konsumen. Seminar Ilmiah Nasional (pp. 77-98). Tangerang Selatan: Program Pascsarjana Universitas Pamulang.

Arianto, N. (2018). Pengaruh Kualitas Pelayanan Terhadap Kepuasan dan Loyalitas Pengunjung Dalam Menggunakan Jasa Hotel Rizen Kedaton Bogor. Kompetitif, 83101.

Arianto, N. (2019). Pengaruh Kualitas Pelayanan dan Promosi Terhadap Kepuasan Konsumen Pada Alfamart . Ekonomi Efektif, 153-160.

Arianto, N. (2019). Pengaruh Promosi dan Kualitas Pelayanan Terhadap Kepuasan Serta Berdampak Terhadap Loyalitas Pelanggan. Kreatif, 44-54.

Ghazali, I. (2013). Aplikasi Analisis Multivariate dengan Program IBM SPSS 21 Upadate PLS Regresi. Semarang: Badan Penerbit Universitas Semarang.

Keller, P. K. (2007). Manajemen Pemasaran, Jilid 1, Ediisi Ke 12. Jakarta: PT Indeks.

Lesmana, R., \& Hasbiyah, W. (2019). Model Analisis Kepuasan dan Loyalitas Wisatawan Lokal Studi Kasus pada Objek Wisata Kepulauan Seribu Jakarta. JIMF (Jurnal IImiah Manajemen Forkamma), 2(3).

Lesmana, R., Sunardi, N., Hastono, H., \& Widodo, A. S. (2021). Perceived Quality Membentuk Customer Loyalty via Brand Equity pada Pengguna Smartphone Merek Xiaomi di Tangerang Selatan. Jurnal Pemasaran Kompetitif, 4(2), 157-167.

Lesmana, R., Widodo, A. S., \& Sunardi, N. (2020). The Formation of Customer Loyalty From Brand Awareness and Perceived Quality through Brand Equity of Xiaomi Smartphone Users in South Tangerang. Jurnal Pemasaran Kompetitif, 4(1), 1-12.

Sugiyono. (2017). Metode Penelitian Kuantitatif, Kualitatif, dan R\&D. Bandung: CV Alfabeta.

Sunardi, N., \& Lesmana, R. (2020). Konsep Icepower (Wiramadu) sebagai Solusi Wirausaha menuju Desa Sejahtra Mandiri (DMS) pada Masa Pandemi Covid19. JIMF (Jurnal IImiah Manajemen Forkamma), 4(1).

Tjiptono, F. (2011). Service Management Mewujudkan Layanan Prima. Edisi 2. Yogyakarta: Andi. 